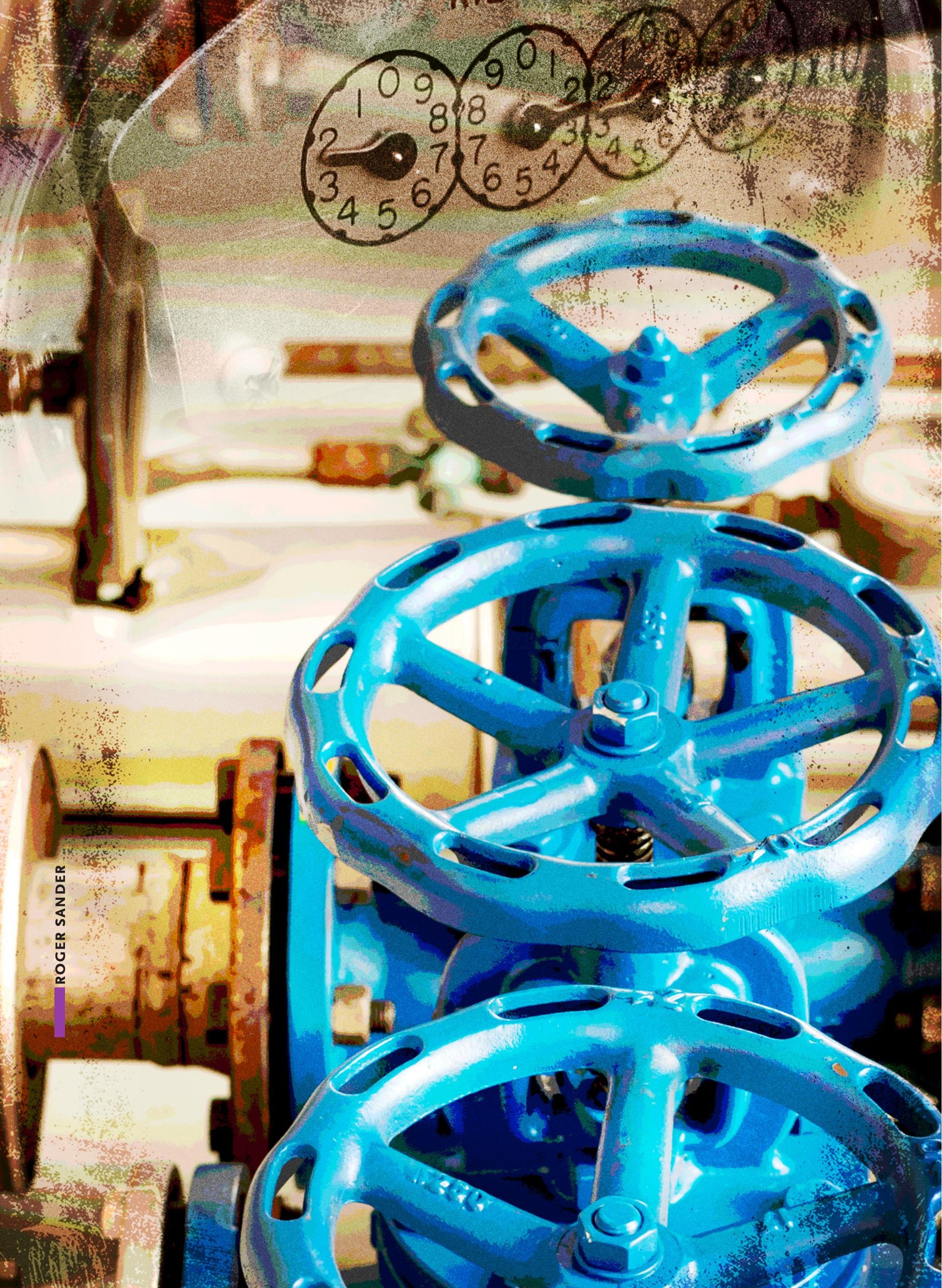




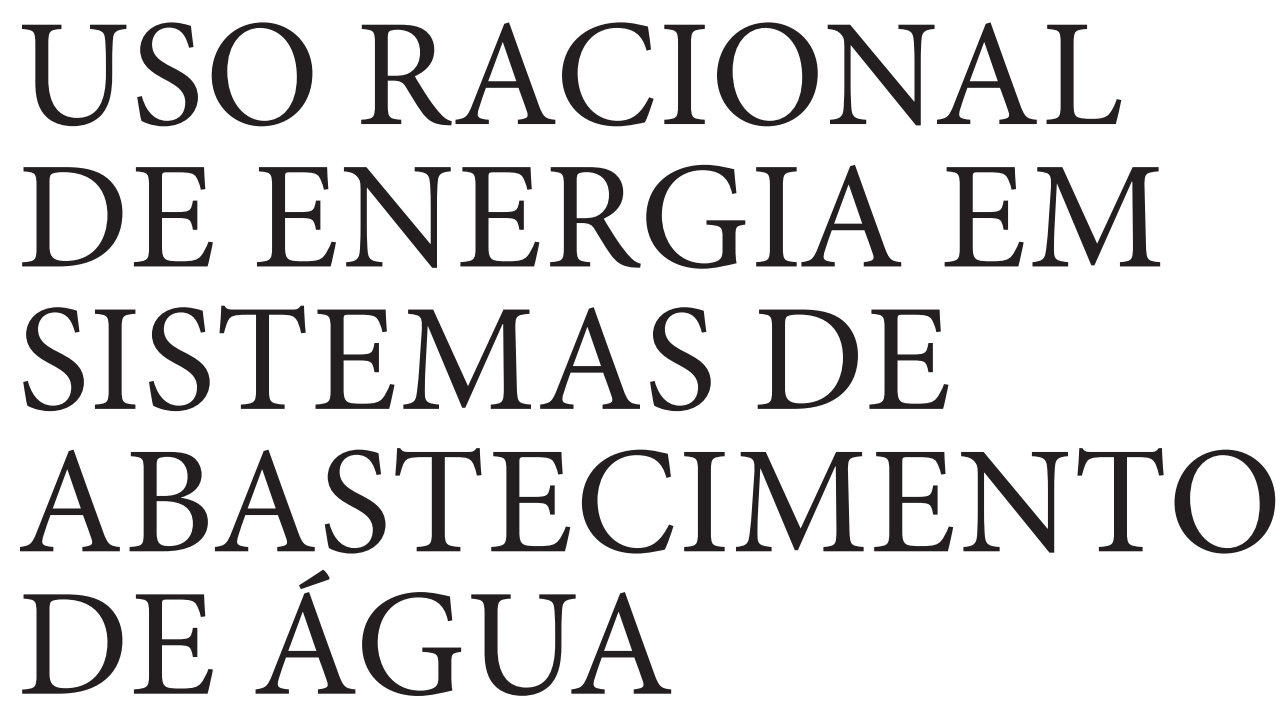

GUSTAVO MEIRELLES LIMA*

BRUNO MELO BRENTAN:*:

RESUmo Os sistemas de abastecimento de água são fundamentais para o desenvolvimento socioeconômico de cidades. Durante muito tempo, seu planejamento e operação eram focados no atendimento da demanda. Entretanto, essa prática não atende às necessidades atuais de uso racional dos recursos naturais. Assim, nos últimos anos, o problema se tornou mais complexo, com a adição de restrições como o consumo de energia e o índice de vazamentos. Assim, este trabalho avaliará duas das principais medidas de eficiência energética que têm sido exploradas: a operação de estações elevatórias e a recuperação de energia em válvulas, apresentando os principais desafios científicos e tecnológicos para sua ampla aplicação. Palavras-chave Abastecimento de água. Eficiência energética. Máquinas hidráulicas.

\section{ENERGY EFFICIENCY IN WATER DISTRIBUTION NETWORKS}

ABSTRACT Water supply systems are essential for social and economic development of cities. For a long time, both planning and management were focused only on attending the demand. However, this practice does not meet the current needs of sustainable use of natural resources. Therefore, in recent years, the problem has become more complex with the addition of constraints such as energy consumption and leakage. Thus, this work will evaluate two of the main energy efficiency actions that have been widely studied: the operation of pumping stations and the energy recovery in valves, showing the main scientific and technological challenges for its wider application.

KEYWORDS Water supply. Energy efficiency. Hydraulic machinery.

* Departamento de Engenharia Hidráulica e Recursos Hídricos, Escola de Engenharia, Universidade Federal de Minas Gerais (UFMG) - gustavo.meirelles@ehr.ufmg.br

** Departamento de Engenharia Hidráulica e Recursos Hídricos, Escola de Engenharia, Universidade Federal de Minas Gerais (UFMG) - brunocivilo8@gmail.com 


\section{Introdução}

inda que, ao longo das últimas décadas, a discussão sobre o crescimento da
demanda por água e energia elétrica tenha ocupado diversas linhas escritas por ambientalistas, pesquisadores, políticos e organizações não governamentais, poucas ações efetivas têm sido implementadas em escalas consideráveis para a preservação e melhoria da qualidade e distribuição da água, sobretudo em meio urbano.

Dado o crescimento da população mundial, estima-se que, em 2050, a demanda por água no mundo será um terço maior do que a atual e que até cinco bilhões de pessoas viverão em regiões de seca intensa ao menos um mês ao ano (BUREK et al., 20I6). Esse processo pode gerar um cenário de forte estresse hídrico, uma vez que, além da maior retirada de água dos mananciais, o volume de resíduos coletado, seja de esgoto doméstico, seja de esgoto industrial, também aumentará. Considerando o cenário atual, em que apenas $59 \%$ do esgoto doméstico (PROGRESS, 20I8) é tratado, há um risco de degradação dos mananciais devido ao lançamento desses efluentes, o que reduziria a oferta de água com qualidade adequada para abastecimento público. O consumo de energia tanto no tratamento dos efluentes quanto da água para consumo será mais intensivo quanto menor for sua qualidade. Por fim, com o elevado grau de urbanização atual, também se intensificam os problemas com a drenagem pluvial, uma vez que a superfície se encontra cada vez mais impermeabilizada. Grandes obras, como reservatórios de acumulação e sistemas elevatórios para retirada da água, podem ser necessárias, causando um impacto ainda maior no consumo de energia das grandes cidades. 
Os sistemas de abastecimento de água, responsáveis por captar, tratar, armazenar e distribuir água potável para diferentes setores, como indústrias e comércios, utilizam energia elétrica em diferentes etapas do processo, desde a captação até a distribuição final. De maneira geral, estudos mostram que de 3 a $7 \%$ da energia elétrica produzida por um país são utilizados nos sistemas de tratamento e distribuição de água e na coleta e tratamento de efluentes (WAKEEL et al., 20ı6). No caso brasileiro, esse valor é de aproximadamente $2 \%$ da produção total de energia elétrica (GUANAIS, COHIM; MEDEIROS, 20I7). Em termos percentuais, isso pode não parecer muito, mas esse valor equivale a $25 \%$ do consumo registrado pelo estado de Minas Gerais em $20 \mathrm{I7}$ (BRASIL, 20I8b) ou, em termos mais práticos, o equivalente ao consumo de mais de 7 mil equipamentos de ar condicionado ligados $24 \mathrm{~h}$ por dia durante um mês, Io mil cafeteiras ligadas $24 \mathrm{~h}$ por dia durante o mês, ou seja, cerca de 320 milhões de xícaras de café por mês.

Grande parte da energia elétrica consumida pelos sistemas de abastecimento de água está associada ao funcionamento de estações elevatórias, transformando a energia elétrica em energia hidráulica, o que possibilita a transposição de zonas elevadas e distantes. Estima-se que seus custos de operação sejam a segunda maior despesa das companhias de água, perdendo apenas para os gastos com recursos humanos.

Uma primeira pergunta que pode ser feita é: como reduzir o consumo de energia nos sistemas de abastecimento? Ou, em outras palavras, quais ações podem ser adotadas para elevar a eficiência das estações elevatórias? A primeira pergunta está diretamente relacionada a intervenções possíveis nas estruturas das estações elevatórias ou na forma de operá-las para se obter, então, uma redução no consumo de energia. No entanto, a segunda pergunta, que versa sobre aumento da eficiência energética do sistema, tem um significado mais profundo. Isso porque a ideia de eficiência não está relacionada apenas ao consumo de energia. Se o sistema de abastecimento fosse capaz de gerar energia elétrica, um saldo positivo no balanço energético existiria e poderia compensar parte da energia consumida.

No desejo de responder às duas questões mencionadas, este trabalho apresenta, nas seções seguintes, ações possíveis para a redução do consumo de energia e formas como a geração distribuída pode auxiliar no aumento da eficiência energética dos sistemas. 


\section{A relação abastecimento de água e energia}

Com o objetivo de inserir energia hidráulica no sistema por meio da energia elétrica, as estações elevatórias são parte fundamental dos sistemas de abastecimento de água e têm especial atenção das empresas, uma vez que são responsáveis por grande parte de seu consumo de energia. De maneira geral, bombas centrífugas acopladas a motores elétricos são utilizadas nesse processo de transformação de energia elétrica em energia hidráulica. O fluido entra pelo centro da parte girante e sai dali escoando no sentido radial das bombas com alta velocidade. Nessa etapa, a energia elétrica foi transformada em energia cinética, transferida então ao fluido pelas partes girantes. Ao escoar no sentido radial, o fluido é captado pela voluta, uma das partes não girantes, onde a energia cinética é transformada em energia de pressão.

Como se pode imaginar, a cada transformação, uma quantidade de energia é perdida. Como resultado final, a eficiência dos conjuntos moto-bomba agrega a eficiência do motor, do rotor, dos cabos e da instalação hidráulica (MORENO, 2007). Muitas vezes superdimensionados, os conjuntos moto-bombas têm sido objeto de estudo há algumas décadas, com o objetivo de melhorar a eficiência energética dos sistemas de abastecimento de água.

Um marco nos estudos de eficiência foi o relatório apresentado pelo Ministério da Defesa dos Estados Unidos da América, no ano de I989, que teve o objetivo de apresentar técnicas para avaliação de sistemas de bombeamento existentes e a criação de rotinas operacionais das bombas. De acordo com esse relatório, o primeiro passo para a melhoria da eficiência das estações elevatórias é a avaliação individual das bombas para identificar a melhor ação a ser implementada.

De maneira geral, as estações elevatórias são dimensionadas a partir de uma curva de perda de carga do sistema, de tal forma que o ponto de operação da estação elevatória esteja o mais próximo possível do ponto de máxima eficiência, como mostra a Figura I, a seguir.

Ainda que possível, a operação no ponto de máxima eficiência é rara em razão das variações de consumo ao longo do dia, manobras de abertura e do fechamento de válvulas. Ou mesmo em razão do envelhecimento das tubulações, comum com o passar do tempo. Todos esses fatores alteram a curva de perda de carga do sistema e, além 
Figura 1 - Ilustração do ponto de operação de um sistema de bombeamento

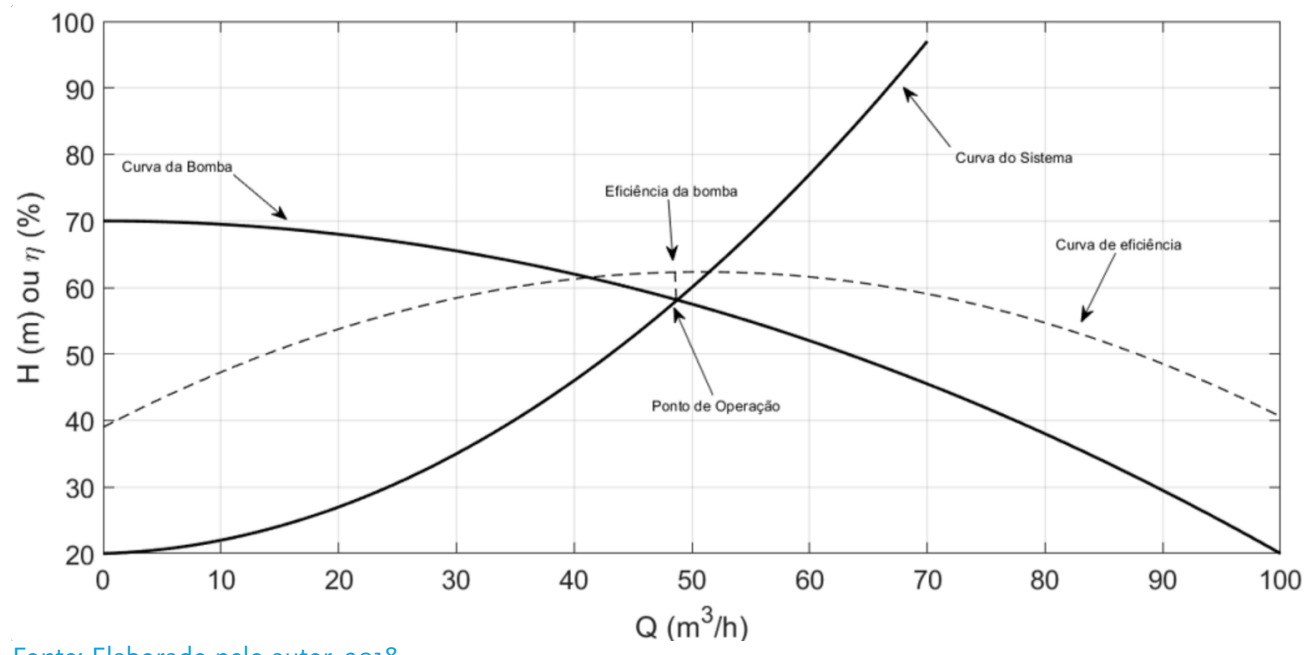

Fonte: Elaborado pelo autor, 2018

deles, normalmente se considera a vazão de projeto majorada, visando a outros horizontes. Isso faz o sistema de recalque operá-la, frequentemente, com vazões diferentes daquelas de projeto e, consequentemente, fora do ponto de máxima eficiência. A Figura 2 mostra o deslocamento da curva de perda de carga de uma linha de recalque. Essa alteração é observada quando é feita a abertura parcial de válvulas, reduzindo a perda de carga no sistema.

Figura 2 - Ilustração da alteração do ponto de operação pela mudança de características do sistema

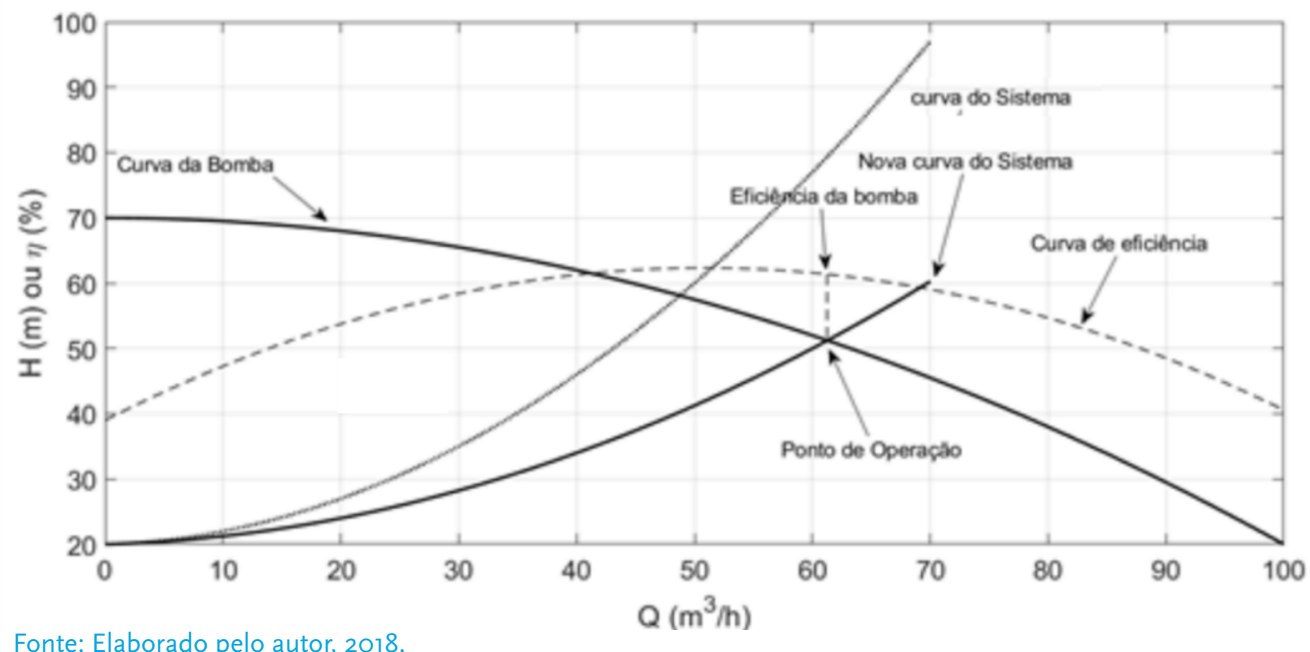

Fonte: Elaborado pelo autor, 2018 


\section{Reduzir o consumo de energia: um desafio possível ou uma ação utópica?}

Observando a Figura 2, uma primeira ideia de controle ótimo de sistemas de abastecimento é identificada. Se a curva opera fora do ponto de máxima eficiência, e manobras de válvulas fazem essa curva se deslocar, é possível determinar o ponto de operação das válvulas de tal forma que, aumentando ou diminuindo a perda de carga, o sistema opere próximo ao ponto de máxima eficiência.

Ainda que essa abordagem seja possível, esse uso não seria suficientemente inteligente. Isso porque o uso de válvulas para regulação do ponto de operação das bombas muda a curva do sistema, adicionando uma perda de carga que outrora não existia. Insere-se uma energia no sistema que precisa ser dissipada, o que começa a não fazer sentido, no contexto da eficiência energética.

Ainda há um outro fator que influencia diretamente no custo de energia, mesmo que provoque diretamente impactos no consumo por parte do bombeamento. De maneira geral, os contratos tarifários preveem custo maior nos horários de pico. Segundo a Eletrobras (BRASIL, 2OII), em um período de três horas consecutivas, definido entre I7h e 2Ih, o consumo em dias úteis tem uma tarifa maior, em razão da maior exigência do sistema elétrico nesse período.

Surgem, então, algumas questões relacionadas às possíveis ações para redução do consumo de energia elétrica e das despesas relativas a esse consumo. A primeira delas é: seria possível operar as bombas fora do horário de pico a fim de que se reduzam os custos envolvidos no bombeamento?

A resposta a essa pergunta é simples, mas ao mesmo tempo bastante vaga: depende da configuração e das necessidades do sistema. Aqueles que têm armazenamento de água com capacidade suficiente possibilitam a elaboração de uma rotina de bombeamento, de tal forma que, nos horários de pico, os consumidores sejam abastecidos apenas por reservatórios que operem por gravidade, enquanto que, fora desse período, as estações elevatórias operam para recuperar seus níveis, bombeando um volume maior que o consumido nesse período.

Problemas de otimização operacional têm sido propostos por meio de uma abordagem matemática desde os primeiros anos da década de I99० (JOWITT e XU, I99०; 
JOWITT; GERMANOPOULOS, I992). A ideia principal por trás dessas abordagens está na minimização do custo relacionado ao bombeamento de água. Esse custo pode ser assim escrito:

$C=\sum_{i=1}^{N} \sum_{t=1}^{T} \frac{Q_{i, t} \cdot H_{i, t} \gamma}{\eta_{i, t}} \cdot c_{t} \cdot \Delta t$

em que $C C$ é o custo total do bombeamento de $N$ bombas para o período de operação de $T$ horas, $Q_{i, t}$ é a vazão bombeada pela bomba $i$ no passo de tempo $t, H_{i, t}$ é a carga inserida no sistema pela bomba $i$ no mesmo passo de tempo, operando com um rendimento $\eta_{i, t}$. A fração dentro do somatório descreve a potência da bomba $i$ no passo de tempo t. Quando essa potência é multiplicada pelo passo de tempo $\Delta t$ e, finalmente, pelo custo da energia no passo de tempo, $c_{t}$, obtém-se o custo individual das bombas para cada passo de tempo. Fica evidente que a minimização ao longo de todo o horizonte $T$ possibilitará que a operação acione ou desligue bombas de tal modo que o consumo seja mínimo.

Ainda que seja intuitivo, é preciso dizer que, caso restrições não sejam impostas, o processo de otimização encontrará um custo de bombeamento igual a zero, deixando todas as bombas desligadas - uma solução matemática plausível, mas operacionalmente errônea. Em problemas de otimização da vida real, as restrições têm papel fundamental para que a solução encontrada seja coerente com o que se espera do problema otimizado.

No caso do controle ótimo de bombas, algumas restrições físicas e operacionais devem ser impostas. Classicamente, as restrições de pressão mínima $\left(P_{\min }\right)$ e máxima $\left(P_{\max }\right)$, atendendo à normativa para o abastecimento de água, níveis máximo $\left(T_{\max , k}\right)$ e mínimo $\left(T_{\min , k}\right)$ de reservatórios, de forma a garantir o atendimento em casos emergenciais e o não transbordamento dos reservatórios são as mais utilizadas (AL-ANI et al., 2OI2; MALA-JETMAROVA; SULTANOVA; SAVIC, 2OI7). Ainda, para evitar o acionamento e desligamento constante das bombas, o que causaria um alto desgaste do motor, um limite de ciclos por dia $\left(m_{\max }\right)$ pode ser estipulado. Transcrevendo matematicamente, o problema de otimização de operação tem a seguinte forma: em que $P_{j, t}$ é a pressão no nó $j$ no passo de tempo $t, T_{k, t}$ é o nível do tanque $k$ no passo 


$$
\begin{aligned}
& \min C=\sum_{i=1}^{N} \sum_{t=1}^{T} \frac{Q_{i, t} \cdot H_{i, t} \gamma}{\eta_{i, t}} \cdot c_{t} \cdot \Delta t \\
& \text { s. } a \\
& P_{\min } \leq P_{j, t} \leq P_{\operatorname{máx}} \\
& T_{\text {min, }} \leq T_{k, t} \leq T_{\text {máx }, k} \\
& m_{i} \leq m_{\text {máx }}
\end{aligned}
$$

de tempo $t$, e $m_{i}$ é o número de ciclos de acionamento e desligamento de bombas para a bomba $i$.

Visando à solução ótima, uma das primeiras abordagens em termos de algoritmo de otimização foi apresentada por Jowitt e Germanopoulos (I992), aplicando a programação linear. Os autores apresentam todo o equacionamento para o problema hidráulico, com as simplificações necessárias ao método, e concluem que, ainda que o método seja efetivo para a determinação das manobras ótimas de bombas, as simplificações do modelo hidráulico podem afetar a solução final.

Yu, Powell e Sterlin (I994), com base no trabalho desenvolvido por Jowitt e Germanopoulos (I992), apresentam a aplicação de uma variante da programação linear baseada no método do gradiente reduzido generalizado com análise de sensibilidade de não linearidade. Essa análise teve o objetivo de reduzir as dificuldades da linearização do problema hidráulico, melhorando o processo de otimização.

O trabalho de Jowitt e Germanopoulos (I992) apresenta uma formulação completa do problema hidráulico, com as restrições operacionais clássicas, mas com técnica de solução menos sofisticada. Por outro lado, anterior a esse trabalho, Zessler e Shamir (I989) apresentaram uma versão do problema hidráulico simplificada, mas com o uso de programação dinâmica para encontrar a rotina ótima de operação. A abordagem via programação dinâmica seria retomada anos mais tarde, com a complementação do problema hidráulico por Lansey e Awumah (I994). Os autores não só deixam de simplificar as equações hidráulicas que regem o funcionamento das redes de abastecimento como inserem a restrição do número de ciclos para o bombeamento.

Ainda que as equações que regem o problema de otimização estejam bem determinadas, o problema matemático a ser resolvido envolve não linearidade e desconti- 
nuidade nas funções, o que torna os métodos clássicos de otimização inaplicáveis em redes de dimensões reais. As simplificações necessárias para aplicação da programação linear ou programação dinâmica deixam o problema com menos detalhes, a ponto de se perder a informação necessária.

Com a popularização do computador e os avanços nas observações e compreensão da natureza, um grupo de algoritmos não derivativos ganhou força para a solução de problemas de engenharia hidráulica, sobretudo nas últimas duas décadas. Esses algoritmos têm como base a busca exaustiva de possíveis soluções ótimas para um problema, em meio a soluções, a priori aleatórias, que são testadas sistematicamente. Entre os métodos de busca exaustiva, os meta-heurísticos têm a vantagem de inserir uma estratégia de melhoria de busca a cada iteração. Diferentemente dos métodos clássicos, cada algoritmo busca estratégias observadas na natureza, para que a iteração seguinte não seja um passo no escuro, mas um passo em direção a uma boa solução (BINITHA; SATHYA, 20I2). Destacam-se métodos baseados na evolução das espécies - Algoritmo Genético (GOLDBERG; KORB; DEB, I989), na busca de cardumes ou pássaros por comida Otimização por Enxame de Partículas (EBERHART; KENNEDY, I995) - e no caminho feito por formigas - Otimização por Colônia de Formigas (DORIGO; DI CARO, I999).

Tendo em conta o desenvolvimento desses algoritmos, principalmente o Algoritmo Genético, os problemas de controle ótimo de bombas passaram a ser abordados com um binômio simulador hidráulico e otimizador bioinspirado. Um dos pioneiros nessa abordagem foi o trabalho apresentado por Brdys et al. (I995). Os autores também integram aspectos de qualidade de água no processo de otimização e utilizam o Algoritmo Genético para a solução do problema. Alguns anos mais tarde, outros algoritmos inspirados na natureza foram aplicados ao controle ótimo de bombas, como é o caso do recozimento simulado (GOLDMAN; MAYS, I999), otimização por enxame de partícula (WEGLEY; EUSUFF; LANSEY, 2000) ou otimização por colônia de formigas (LÓPEZ-IBAÑNS; PRASAD; PAECHTER, 2008).

Com o advento do simulador hidráulico de código aberto Epanet 2.0 e sua versão programável (ROSSMAN, 2000), a integração das equações hidráulicas a códigos de otimização ficou mais simples. A literatura corrobora essa afirmação, tendo em vista os diversos artigos publicados entre 2000 e 2010 utilizando algoritmos bioinspirados e 0 simulador hidráulico (MALA-JETMAROVA; SULTANOVA; SAVIC, 2OI7). 


\section{Otimizando a operação otimizada}

Retomando o problema hidráulico de eficiência energética, observa-se que o ponto de operação das bombas (FIG. 2) pode estar deslocado do ponto de máxima eficiência, o que conduz à seguinte pergunta: seria possível deslocar a curva das bombas e consequentemente, a curva de eficiência a fim de que o ponto de operação do sistema fosse o mais próximo possível do ponto de máxima eficiência? Sendo possível, como esse artifício poderia ser escolhido de maneira ótima?

Os parâmetros hidráulicos das bombas seguem as leis de semelhança que podem ser facilmente obtidas por meio da análise dimensional, como mostrado por Stepanoff e Stahl (I96I). Considerando o mesmo fluido e a mesma máquina hidráulica, algumas relações de semelhança em termos de carga, vazão e potência podem ser obtidas, como apresentado nas Equações (3-5),

$$
\begin{aligned}
& \frac{Q_{1}}{Q_{2}}=\frac{n_{1}}{n_{2}} \\
& \frac{H_{1}}{H_{2}}=\left(\frac{n_{1}}{n_{2}}\right)^{2} \\
& \frac{\operatorname{Pot}_{1}}{\operatorname{Pot}_{2}}=\left(\frac{n_{1}}{n_{2}}\right)^{3}
\end{aligned}
$$

em que $Q_{1}$ é a vazão bombeada pela bomba sob rotação $n_{1}$, adicionando uma carga $H_{1}$, com uma potência $P_{1}$. O subíndice 2 representa as condições hidráulicas para a rotação $n_{2}$. Seguindo as leis de semelhança, curvas de carga x vazão diferentes daquelas em rotação nominal podem ser encontradas e, consequentemente, novos pontos de operação. Do ponto de vista prático, a variação da rotação pode ser obtida via uso de inversores de frequência, que, desde os anos 2000, vêm sendo instalados nas estações de bombeamento do Brasil, principalmente para maior segurança das operações de parada e partida de bombas. Uma importante característica que provém das relações adimensionais é a curva de pontos homólogos. Para um determinado rendimento $\eta$, a bomba operando na rotação nominal terá um par carga-vazão $\left(Q_{n}, H_{n}\right)$, conhecido 
pela curva do fabricante. Dessa forma, é possível determinar um conjunto de pares carga-vazão, em diferentes rotações, que terão o mesmo rendimento da bomba operando na rotação nominal, conhecidos como pontos homólogos. A Figura 3 mostra as curvas carga x vazão para algumas rotações relativas $\left(\alpha=\frac{n_{1}}{n_{2}}\right)$.

Figura 3 - Representação de curvas de bomba com rotação diferente da nominal e representação da curva de pontos homólogos

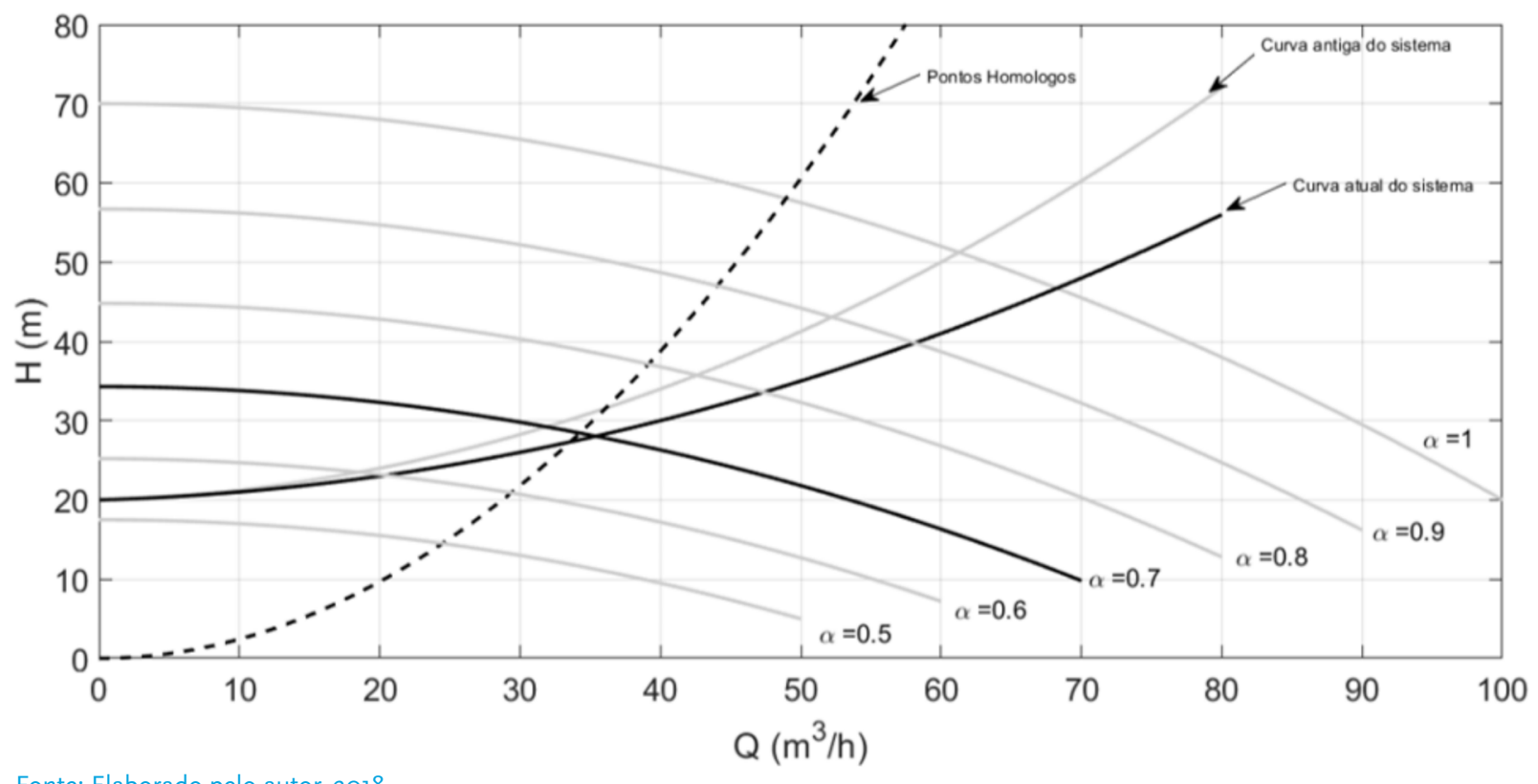

Fonte: Elaborado pelo autor, 2018.

Dada a possibilidade de operações não binárias, ou seja, a possibilidade de escolher uma certa rotação relativa para que as bombas operem sempre no seu ponto de máxima eficiência, alguns trabalhos aplicaram métodos de otimização para encontrar um cenário ótimo de rotações ao longo de um horizonte operacional (BRENTAN et al., 20I5; BRENTAN et al., 20I8; LINGIREDDY; WOOD, I998; RIBEIRO, 2007; RODRIGUES, 2007; SHAMIR; SALOMONS, 2008).

De maneira geral, os trabalhos que abordam a operação ótima de bombas via inversor de frequência utilizam o mesmo equacionamento matemático apresentado na Equação (I). No entanto, carga, vazão e rendimento dependem da rotação relativa $\alpha$, como se observa na Figura 3. 
Se do ponto de vista hidráulico e matemático as diferenças são pouco significativas, do ponto de vista computacional, o problema de trabalhar com variáveis contínuas (rotação específica) no lugar de variáveis binárias (o status operacional das bombas) torna o processo de convergência dos algoritmos mais lento e, por sua vez, computacionalmente mais custoso. Ainda assim, como apresentado por Brentan et al. (20I8), o uso de operações via inversor de frequência pode trazer ganhos ainda maiores para as empresas de água quando comparado à operação otimizada apenas com ciclos de acionamento das bombas.

\section{As outras variáveis do problema de eficiência energética}

Um gargalo importante no controle ótimo está na demanda. Qual demanda deverá ser atendida pelo sistema de abastecimento de forma que as bombas operem de maneira ótima? Via de regra, essa demanda é desconhecida e adota-se uma demanda média de um determinado setor. Ainda que essa abordagem responda bem aos dias típicos, o uso da demanda média faz o sistema ainda não trabalhar em sua máxima eficiência.

Nos últimos anos, devido ao avanço da coleta de dados referentes à vazão distribuída, as abordagens híbridas previsão-otimização ganharam força na literatura. Essas abordagens possibilitam não só o controle ótimo para um conjunto moto-bomba, mas também o conhecimento prévio da demanda a ser bombeada, o que torna possível a determinação do ponto de operação de máxima eficiência.

Desde meados dos anos 2000 , técnicas de previsão de demanda aplicadas ao controle ótimo têm aparecido na literatura (MARTINEZ et al., 2007). Via de regra, algoritmos de aprendizado de máquinas são aplicados para previsão de demanda, que, acoplados ao simulador hidráulico, possibilitam a atualização das demandas nodais. Por sua vez, o simulador hidráulico serve de base para os cálculos das variáveis fundamentais no processo de otimização do controle. Nessa abordagem tríplice, destacamse os trabalhos de Brentan et al. (2018), Broad, Maier e Dandy (2010), Martinez et al. (2007), Odan, Reis e Kapelan (2015) e Rao e Salomons (2007).

Se de um lado as ferramentas computacionais de otimização mono-objetivo são as mais populares na literatura $(87 \%$ dos trabalhos de controle ótimo de bombas em 
abastecimento de água abordam otimização mono-objetivo, segundo Mala-Jetmarova, Sultanova e Savic (20I7)), essas abordagens devem necessariamente tratar as restrições do problema, tarefa árdua e campo aberto para discussões, como apresentado por Manzi et al. (2018).

Além disso, olhando para o problema de controle ótimo, ainda que o ganho em eficiência energética seja o primário e mais importante, um segundo componente pode aparecer, relativo à redução de pressão excessiva na rede. Ao reduzir o consumo de energia das bombas, tende-se a reduzir as pressões nas redes e, consequentemente, diminuir as perdas físicas por vazamento. Esse ganho poderia ser inserido no processo de otimização, desde que se deseje maximizar a eficiência energética e maximizar a redução de perdas. No entanto, para algoritmos mono-objetivo, o trabalho com grandezas distintas pode ser tarefa difícil.

Como forma de lidar com as restrições e a otimização de objetivos distintos, os algoritmos multiobjetivos também ganharam força na busca pelo controle ótimo de redes de abastecimento de água. Por serem capazes de trabalhar com diversos objetivos ao mesmo tempo, as restrições do problema físico podem ser trabalhadas como objetivos almejados. Por exemplo, em vez de criar uma penalização para a pressão mínima, busca-se minimizar o déficit de pressão na rede, representado pela diferença entre a pressão mínima e a pressão operacional (CARPITELLA et al., 20I8).

Com essa abordagem, seja visando à operação de ciclos de acionamento (otimização binária) ou o conjunto de rotações ótimas (otimização contínua), diversos trabalhos são apresentados na literatura (BARÁN; VON LÜCKEN; SOTELO, 2005; CARPITELLA et al., 20I8; LÓPEZ-IBAÑNS; PRASAD; PAECHTER, 2005; ODAN; REIS; KAPELAN, 20I5; SAVIC; WALTERS; SCHWAB, I997).

Ainda que vantajoso para o tratamento de problemas com restrições, os algoritmos multiobjetivos não apresentam uma única solução ótima, mas um conjunto de soluções, chamado de frente Pareto. Esse conjunto tem a característica de não dominância entre soluções, ou seja, dentro desse conjunto, todas as soluções são ótimas, a depender do objetivo observado. Dessa forma, o operador ainda precisa realizar uma decisão sobre a qual solução ótima que será implementada a cada instante. Como auxílio a essa tomada de decisão e visando à escolha automática da solução ótima para o controle em tempo real, Carpitella et al. (20I8) apresentam um pós-processamento da frente Pareto 
utilizando análise multicritério. Essa análise, baseada na experiência dos operadores, ordena as soluções da frente Pareto de acordo com uma série de critérios. Dessa forma, os operadores podem implementar a solução que tem maior compromisso com os critérios eleitos.

Como é possível observar, muitas são as abordagens, tanto em termos hidráulicos quanto matemáticos e computacionais, para o controle ótimo de bombas nos sistemas de abastecimento. Mesmo que amplamente explorada na literatura, a busca por eficiência nas estações elevatórias é ainda campo vasto para pesquisas e sobretudo para aplicações práticas por parte das empresas. Além disso, é preciso pensar na eficiência energética do sistema integralmente. Ou seja, além de reduzir o consumo por parte das estações elevatórias, é fundamental ter em conta possíveis fontes de geração de energia a fim de que o balanço consumo-produção possa ser melhorado.

\section{Consumir energia para abastecer ou abastecer para gerar energia?}

Como visto anteriormente, as estações elevatórias são fundamentais para o abastecimento de água, já que possibilitam que grandes desníveis e distâncias entre o ponto de consumo e a captação sejam superados. Entretanto, essa operação exige uma grande quantidade de energia, e, portanto, as medidas de eficiência citadas são fundamentais para que os recursos naturais sejam utilizados de forma racional e sustentável.

Contudo, existem casos em que esse cenário é oposto: a captação está localizada em uma altitude superior ao ponto de consumo e uma distância relativamente pequena. Soffia et al. (20I0) e Kougias et al. (20I4) citam regiões montanhosas da Itália, Áustria e Suíça onde esse cenário é comum. Dessa forma, a energia utilizada para o abastecimento é a gravitacional, ou seja, não há necessidade de estações elevatórias e, consequentemente, o consumo de energia elétrica é nulo. Nesse contexto, surge a seguinte questão: um sistema onde não há consumo de energia elétrica é considerado I0০\% eficiente? A Associação Brasileira de Empresas de Serviço de Conservação de Energia (ABESCO, s.d.) define eficiência energética como a relação entre a quantidade 
de energia empregada em uma atividade e aquela disponibilizada para sua realização. A Empresa de Pesquisa Energética (BRASIL, 20I8b), por sua vez diz que a eficiência energética consiste em obter o mesmo serviço, com a mesma qualidade e quantidade, mas com um menor consumo de energia e recursos naturais.

Ao aplicar essas definições no caso do abastecimento de água por gravidade, é possível identificar um ponto de ineficiência no sistema: as Válvulas Redutoras de Pressão (VRPs). Essas válvulas inserem uma perda de carga ao sistema para evitar que pressões elevadas causem danos às tubulações. Ou seja, parte da energia gravitacional empregada no abastecimento de água está sendo dissipada no processo, na forma de perda de carga localizada e não é efetivamente empregada no "serviço" de fornecimento de água, deixando o sistema menos eficiente.

Além disso, outra característica deve ser levada em conta para determinar a eficiência energética do abastecimento de água. A energia potencial leva em consideração, além do desnível geométrico, a massa do corpo, nesse caso representado pelo volume de água que deve ser transportado. É de se esperar que esse volume seja igual ao volume de água consumido. Entretanto, em razão das imperfeições no assentamento das tubulações, envelhecimento de juntas e pequenas rupturas, vazamentos ocorrem constantemente nas redes de distribuição. No Brasil, de acordo com o Sistema Nacional de Informações Sobre Saneamento (BRASIL, 20I8a), a perda de água na distribuição é de 38\%. Esse número está bem acima dos níveis atingidos por cidades de referência como Melbourne e Copenhague, que têm perdas da ordem de 5\% (HAMANAKA, 20I7). O aumento do investimento no combate às perdas poderia melhorar esse desempenho, mas, como ressaltam Islam e Babel (2013), existe um limite econômico em que o investimento necessário não gera uma economia de água e energia suficientes para que a ação seja viável, principalmente devido ao fato de que a localização de vazamentos de pequeno porte é uma tarefa difícil (MOSER; PAAL; SMITH, 2OI5).

Consertar vazamentos é uma tarefa complexa e onerosa, o que tem sido feito amplamente é minimizar o volume de água perdido, reduzindo-se a pressão do sistema, uma vez que esses dois parâmetros estão diretamente relacionados conforme a Equação (6). Assim, apesar de desperdiçarem parte da energia potencial, as VRPs exercem um papel importante nos sistemas de abastecimento de água, pois, ao reduzirem a pressão nas redes de distribuição, diminuem o desperdício de água em vazamentos. 
Consequentemente, o volume total de água necessário para abastecimento será reduzido, ou seja, a energia potencial disponível será utilizada de forma mais eficiente.

$Q_{2}=Q_{1} \cdot\left(\frac{p_{2}}{p_{1}}\right)^{n}$

onde $Q_{2}$ é a vazão do vazamento após o controle de pressão, $Q_{1}$ é a vazão de vazamentos sem controle de pressão, $p_{1}$ é a pressão inicial do sistema (sem VRP), $p_{2}$ é a pressão da rede de distribuição após a instalação da VRP, e $n$ é um expoente que depende do material da tubulação.

Surge, pois, a questão: é possível aproveitar a energia dissipada pelas VRPs e ainda assim realizar o controle de pressão na rede de distribuição? Muhammetoglu et al. (20I8) apresenta uma instalação piloto da cidade de Antalya, na Turquia, em operação desde 20ı6, que demonstra a viabilidade técnica e econômica dessa alternativa. Contudo, essa aplicação não é simples e requer estudos detalhados que serão descritos a seguir. Desse modo, sistemas de abastecimento de água que operem por gravidade poderão efetivamente se tornar mais eficientes com relação ao consumo de energia.

\section{Como identificar um potencial energético em um sistema de abastecimento de água?}

Os sistemas de abastecimento de água são compostos de diversos subsistemas interligados por tubulações e canais, conforme ilustra a Figura 4. As adutoras são tubulações que transportam um grande volume de água, normalmente entre a captação e a estação de tratamento ou entre reservatórios de água tratada. Caso essas adutoras operem com energia gravitacional, é possível realizar o aproveitamento energético integral do excesso de pressão nesses locais, uma vez que a água é descarregada à pressão atmosférica nos reservatórios, como indicado na Figura 4, no transporte de água tratada da estação de tratamento ao reservatório principal da cidade. Apesar de se assemelharem com pequenas centrais hidrelétricas, os potenciais existentes nesses locais, conforme Afshar, Jemma e Mariño (I990), podem ser comprometidos devido ao excesso de perda de carga nas tubulações, uma vez que elas são projetadas apenas para 
transporte de água, sem considerar a geração de energia, ou seja, são dimensionadas para que seu diâmetro seja o menor possível, reduzindo os custos de instalação. Lima et al. (20I8) demonstram que o custo relativo a um pequeno aumento no diâmetro dessas tubulações é amplamente superado pelo benefício obtido com a geração de energia proporcionada.

Figura 4 - Locais com potencial para geração de energia em um sistema de abastecimento de água

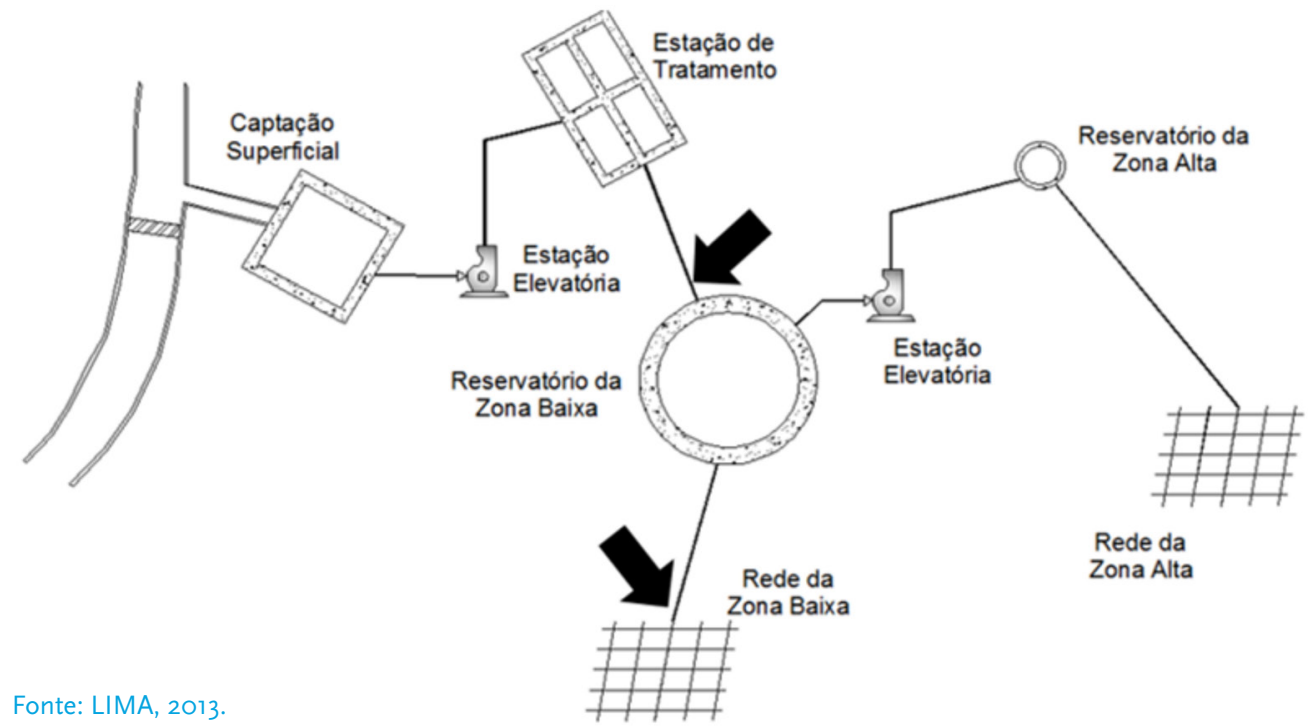

As redes de distribuição de água, por sua vez, têm uma configuração complexa, com a possível formação de anéis de distribuição que possibilitam que a água seja distribuída por diferentes caminhos de acordo com o consumo populacional, aumentando, assim, sua confiabilidade. Além disso, as redes de distribuição de água devem operar com uma pressão mínima para evitar a intrusão de patógenos por rupturas e para garantir o funcionamento de equipamentos hidrossanitários nas residências. Assim, identificar o trecho em que é possível realizar o aproveitamento energético não é uma tarefa simples e requer estudos técnicos e econômicos para garantir qualidade operacional do sistema. Lima, Brentan e Luvizotto Junior (20I7b) propõem identificar o trecho que maximize o benefício obtido no sistema, ou seja, aquele que seja capaz de gerar a maior quantidade de energia e reduzir com mais eficiência o volume de vazamentos. Apesar dos bons resultados, os autores ressaltam que essa metodologia se baseia exclusivamente no critério econômico, podendo resultar em uma configuração em que o controle de vazamentos seja preterido à geração de energia. 


\section{Bomba centrífuga: um equipamento multifuncional}

Uma das grandes questões relacionadas ao aproveitamento energético em sistemas de abastecimento de água é sua viabilidade econômica. Ao contrário de usinas hidrelétricas convencionais, onde barragens e reservatórios são construídos para elevar quedas disponíveis e regularizar o fluxo de água, em sistemas de abastecimento de água, essas variáveis são dependentes do consumo da população e, em geral, propiciam um potencial energético muito inferior ao de usinas hidrelétricas.

Essa característica exige que o projeto tenha custos reduzidos para que seja viável economicamente. Nesse cenário, os equipamentos eletromecânicos, turbina e gerador, representam a maior parcela do investimento necessário (CHAPALLAZ; EICHENBERGER; FISCHER, I992). Isso se deve ao fato de esses equipamentos serem fabricados sob demanda, ou seja, eles são produzidos de acordo com as características do empreendimento, o que os torna um produto único. Entretanto, os rotores de turbinas e bombas se assemelham geometricamente, apresentando um fluxo radial em seu interior. Na realidade, as máquinas hidráulicas são capazes de operar em diferentes zonas de acordo com o sentido de sua rotação, altura e vazão (WYLIE; STREETER; SUO, I993). O mesmo ocorre com os motores de indução, que podem trabalhar como geradores. A Figura 5 ilustra as curvas características de uma máquina

Figura 5 - Curvas características de uma máquina hidráulica operando como bomba e turbina

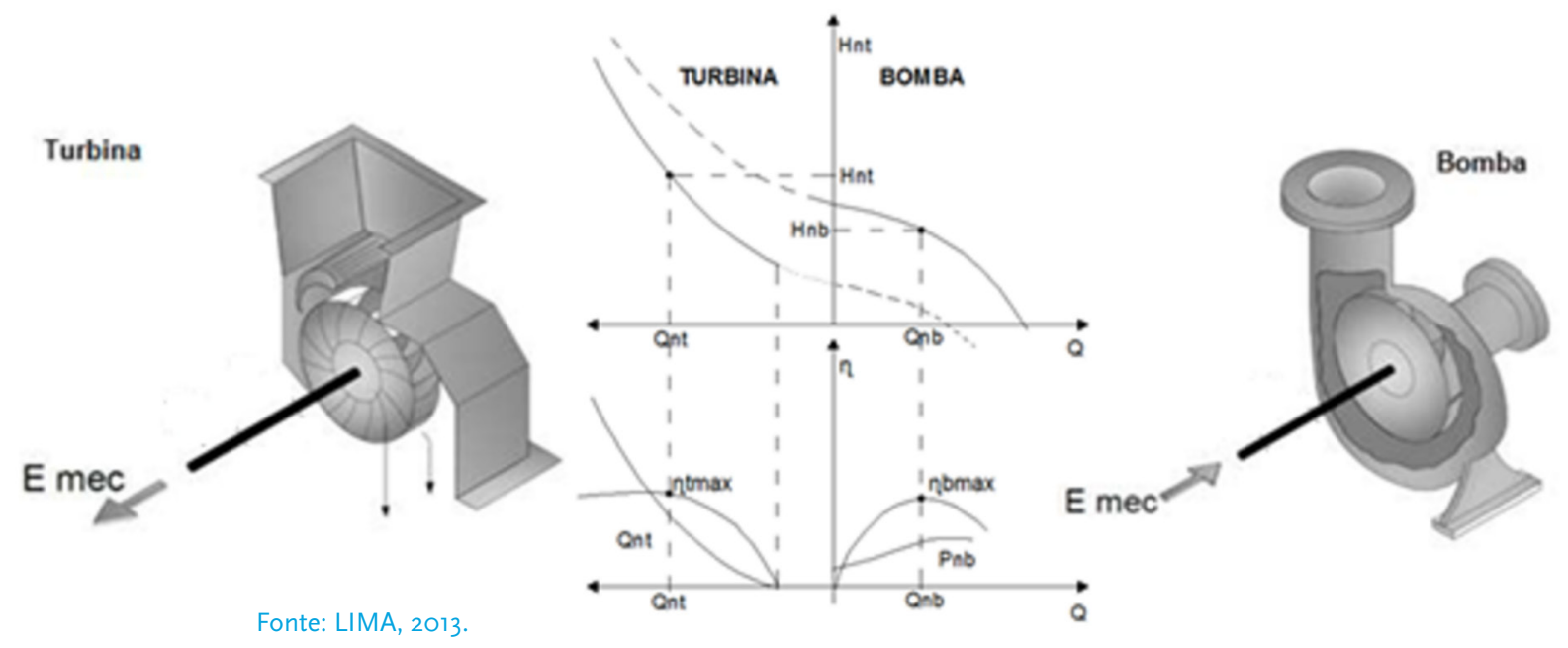


hidráulica funcionando como bomba e turbina com suas vazões, alturas e potências nominais $-Q_{n b}, H_{n b}, P_{n b}$ e $Q_{n t}, H_{n t}, P_{n t}$ respectivamente, e também o sentido do fluxo da energia mecânica $E_{\text {mec }}$. Assim, surgiu a ideia de se utilizar bombas e motores, que são equipamentos fabricados em série, para realizar a geração de energia elétrica, reduzindo significativamente o custo dos equipamentos eletromecânicos.

Diversos estudos foram feitos mostrando viabilidade técnica e econômica das bombas para a geração de energia elétrica em sistemas de abastecimento de água. Assim, a bomba hidráulica, projetada para recalcar água, é utilizada tanto como turbina quanto como válvula, gerando energia elétrica e reduzindo os vazamentos na distribuição. Apesar de ser um sistema relativamente eficiente, quando comparada aos equipamentos específicos, o rendimento da bomba, tanto na geração de energia quanto no controle de vazamentos, é inferior, conforme mostra a Figura 6, em que é possível verificar a grande variabilidade de pressão na rede de distribuição ao longo do dia, diferentemente da operação observada em uma VRP, em que a pressão se mantém constante.

Figura 6 - Controle de pressão em uma rede de abastecimento de água utilizando bomba funcionando como turbina - BFT

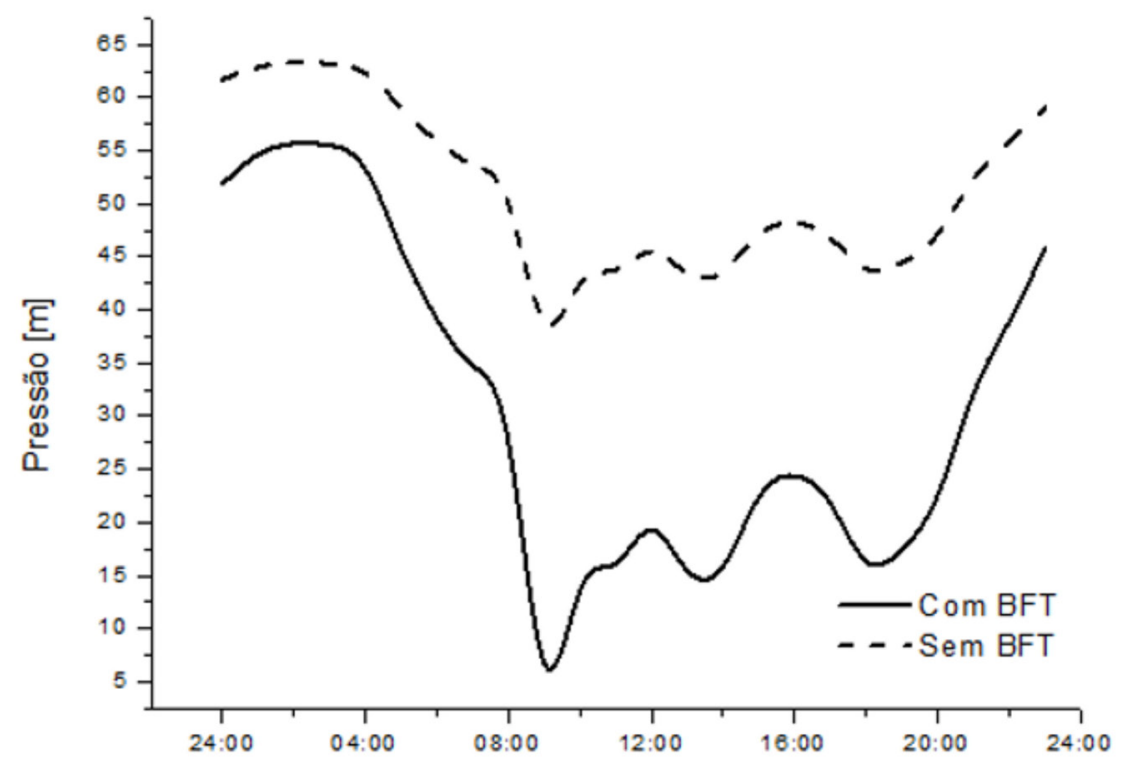

Fonte: LIMA, 2013. 


\section{A eficiência do aproveitamento energético}

Do ponto de vista teórico, o aproveitamento energético e o controle de vazamentos simultâneos conseguidos por meio de bombas que funcionam como turbinas (BFTs) são excelentes, uma vez que os recursos são explorados de forma otimizada. Entretanto, em razão da baixa eficiência, tanto na geração de energia quanto no controle de vazamentos, sua aplicação em casos reais se torna questionável. Assim, diversos estudos foram realizados de forma a melhorar a performance global das BFTs.

A primeira alternativa proposta, feita por Carravetta et al. (20I2), baseia-se no uso de BFTs em paralelo com VRPs já existentes. Dessa forma, o controle de vazamentos se mantém com uma alta eficiência devido à operação da VRP, mas a geração de energia é reduzida, uma vez que a BFT turbinará apenas uma parcela da vazão disponível.

Outra proposta feita por Carravetta, Fecarotta e Ramos (20I8) é utilizar múltiplas BFTs em série e/ou em paralelo para operar com as diferentes pressões e vazões observadas ao longo do dia. Os autores ressaltam ainda que as máquinas podem ser dimensionadas diferentemente, considerando as características de períodos de menor e maior consumo para que operem com maior eficiência nessas condições. Essa alternativa visa realizar tanto o controle de vazamentos quanto a geração de energia de forma integral, garantindo uma grande eficiência do sistema. Entretanto, a complexidade operacional de um sistema com múltiplas BFTs e os custos de implantação são barreiras para a aplicação dessa alternativa.

Por fim, Lima et al. (20I7a) propõem o uso da rotação variável para atender às variações de vazão e pressão durante o dia. Dessa forma, quando o consumo é elevado, a rotação da máquina é reduzida para que a perda de carga produzida seja menor, uma vez que a pressão disponível também é menor. Já no caso contrário, no período onde o consumo é reduzido, a máquina pode operar com uma rotação alta para gerar uma perda de carga elevada e, assim, reduzir a pressão na rede de distribuição. Essa alternativa agrega os mesmos benefícios de se utilizar múltiplas BFTs, mas de forma simplificada, pois apenas uma máquina deve ser controlada. Entretanto, os autores sugerem que, em locais onde a amplitude do consumo de água é elevada, a eficiência operacional dessa alternativa se reduz, sendo necessária a adição de uma outra BFT ou uma VRP para que se atinja uma performance satisfatória. O campo de operação de cada uma das alternativas apresentadas é ilustrado na Figura 7. 
Figura 7 - Opções para uso de BFTs em redes de abastecimento de água: a) Múltiplas BFTs em paralelo; b) BFT associada em paralelo a uma VRP; c) BFT com rotação variável

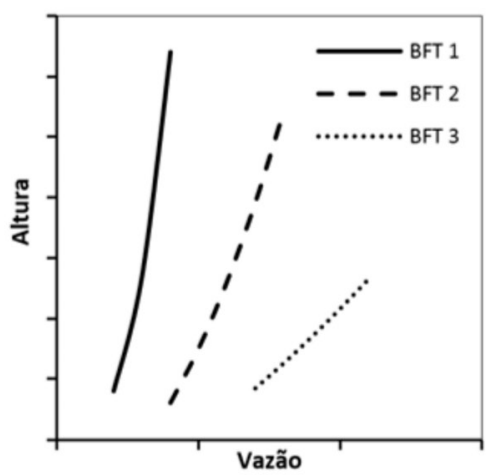

(a)

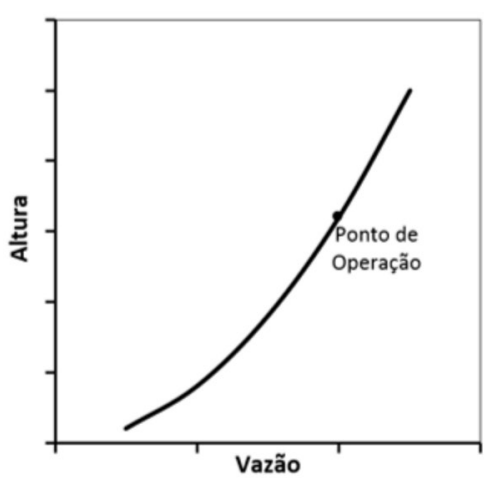

(b)

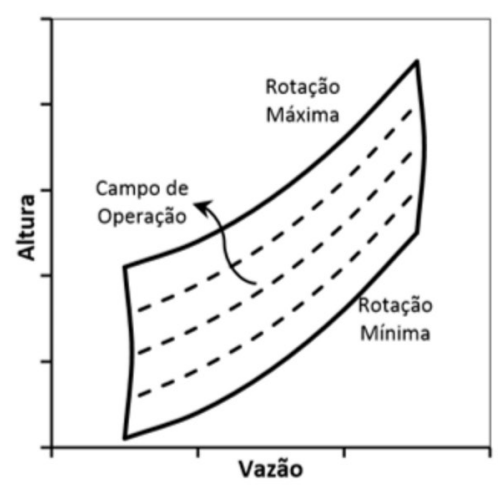

(c)

Fonte: LIMA, 2017C.

\section{Perspectivas}

O crescimento da demanda de água, associada à escassez de recursos hídricos em grandes centros urbanos implica a exploração de mananciais cada vez mais distantes, o que faz elevar o consumo de energia para a produção de água tratada em razão, principalmente, da presença de estações elevatórias de grande porte. Silva Filho (20I2) apresenta diversas ações de eficiência energética, como substituição de conjuntos moto-bombas, operação otimizada de estações elevatórias e limpeza de tubulações, demonstrando a grande viabilidade das ações de eficiência energética em estações elevatórias, com taxas de retorno variando de seis meses a dois anos. Lima (2013) também apresenta estudos sobre a viabilidade da geração de energia em sistemas de abastecimento de água, onde a taxa de retorno varia de um a cinco anos. Entretanto, o desenvolvimento e o aperfeiçoamento de tecnologias e rotinas operacionais ainda são necessários para reduzir a demanda desses insumos fundamentais para o desenvolvimento das cidades.

Entre os pontos ainda em aberto para discussão e inovação no que tange ao controle ótimo de redes, pode-se citar o aumento da eficiência computacional para abordagens em tempo real, a simulação de falhas para definição de controle em situações anômalas ou ainda a representação das perdas de maneira mais fidedigna às situações encontradas em campo. 
A abordagem em tempo real pode trazer ganhos significativos para a operação dos sistemas de abastecimento. Isso porque válvulas e bombas são operadas de acordo com a demanda em tempo real, reduzindo ainda mais o excedente de pressão e o consumo de energia (BRENTAN et al., 20I8). No entanto, tão complexa é essa abordagem quanto vantajosa para os sistemas de abastecimento. Isso porque o desafio de operação em tempo real passa pelo conhecimento do comportamento das redes frente às manobras e também do padrão de consumo por parte dos usuários. Além disso, operações remotas em tempo real devem ter em conta as possíveis falhas do sistema, de tal modo que sejam capazes de implementar controles ótimos, mesmo em situações de anomalia. Daí, a dificuldade dessa abordagem e a importância do monitoramento das redes.

No que se refere à produção de energia nas redes de abastecimento, Carravetta et al. (20ı8) destacam na Europa as ações do grupo de pesquisa REDAWN (Reducing Energy Dependency in Atlantic Water Networks), que busca desenvolver o aproveitamento de energia em redes de abastecimento de água. Nos EUA, a EPA (Environmental Protection Agency) tem diretrizes e planilhas para que as concessionárias de água façam o uso eficiente da energia, inclusive considerando a geração de energia nas redes de distribuição. No Brasil, podem ser destacados os esforços do Procel (Programa Nacional de Conservação de Energia Elétrica) ao desenvolver a etiquetagem de conjuntos moto-bombas em 20 Io (Brasil, 20IO), da Aneel, ao estabelecer em 20I2 condições para que microgeradores tivessem acesso às redes de distribuição (Aneel, 20I2), e do Ministério das Cidades, ao criar o Sistema Nacional de Informações sobre Saneamento (SNIS), em I996, como ferramenta de auxílio no planejamento, gestão e avaliação de desempenho do setor de saneamento (Brasil, 20I8). Atualmente, a eficiência energética de sistemas de abastecimento de água passa pelo conceito de Smart Cities, em que a tecnologia da informação é utilizada para obter soluções otimizadas em um curto espaço de tempo. Assim, o desenvolvimento de sensores, softwares de análise de dados e a operação integrada com outras infraestruturas urbanas deverão ser o foco de estudo nos próximos anos. 


\section{Referências}

AGÊNCIA NACIONAL DE ENERGIA ELÉTRICA, Resolução Normativa Aneel n. 482, de I7 de abril de 2012 (Diário Oficial, de I9 abr. 20I2, seção I, p. 53), 2012.

AFSHAR, A.; JEMAA, F. B.; MARIÑO, M. A.. Optimization of hydropower plant integration in water supply system. Journal of Water Resources Planning and Management, v. II6, n. 5, p. 665-675, I990. DOI: https://doi.org/10.I06r/(ASCE)0733-9496(I990)116:5(665)

AL-ANI, D.; HABIBI, S.. Optimal pump operation for water distribution systems using a new multi-agent Particle Swarm Optimization technique with EPANET. In: 20I2 25th IEEE Canadian Conference on Electrical and Computer Engineering (CCECE). IEEE, 20I2. p. I-6.

ASSOCIAÇÃO BRASILEIRA DE EMPRESAS DE SERVIÇO DE CONSERVAÇÃO DE ENERGIA - Abesco. O que é Eficiência Energética? (EE). [s.d.]. Disponível em: http://www.abesco.com.br/pt/oque-e-eficiencia-energetica-ee/. Acesso em: 8 nov. 2019.

BARÁN, B.; VON LÜCKEN, C.; SOTELO, A. Multi-objective pump scheduling optimisation using evolutionary strategies. Advances in Engineering Software, v. 36 , n. I, p. 39-47, 2005. DOI: https:// doi.org/IO.IOI6/j.advengsoft.2004.03.012

BINITHA, S.; SATHYA, S. S. A survey of bio inspired optimization algorithms. International Journal of Soft Computing and Engineering, v. 2, n. 2, p. I37-I5I, 2012.

BRASIL. Ministério Do Desenvolvimento, Indústria E Comércio Exterior Instituto Nacional De Metrologia, Normalização E Qualidade Industrial-Inmetro. Portaria $n^{\circ} 455$, de I de dezembro de 20 Io.

BRASIL. Ministério das Cidades. Programa Nacional de Conservação de Energia Elétrica-Procel. Manual de tarifação da energia elétrica. Brasília, 20II.

BRASIL. Ministério das Cidades. Secretaria Nacional de Saneamento Ambiental. Sistema Nacional de Informações sobre Saneamento. Diagnóstico dos serviços de água e esgotos - 20ı6. Brasília: SNSA/ MCIDADES, 20I8a. 220 p. Disponível em: http://www.snis.gov.br/diagnostico-agua-e-esgotos/ diagnostico-ae-20I6. Acesso em: 8 nov. 20I9.

BRASIL. Ministério de Minas e Energia (MME). Empresa de Pesquisa Energética (EPE). Balanço Energético Nacional 20I8 - Ano Base 20I7. Rio de Janeiro: MME, 20I8b. Disponível em: http:// epe.gov.br/sites-pt/publicacoes-dados-abertos/publicacoes/PublicacoesArquivos/publicacao-303/ topico-4I9/BEN20I8__Int.pdf. Acesso em: ०8 nov. 2019.

BRDYS, M. A et. al. Operational control of integrated quality and quantity in water systems. IFAC Proceedings Volumes, v. 28, n. Io, p. 663-669, I995. DOI: https://doi.org/Io.IoI6/Si4746670(I7)51596-7

BRENTAN, B. et al. Water pump scheduling optimization using agent swarm optimization. In: International Conference on Mathematical Modelling in Engineering \& Human Behaviour, 20I5, Valencia. Proceedings [...]. Valencia: IMM, 2015, p. 50-55. 
BRENTAN, B. et al. Joint Operation of Pressure-Reducing Valves and Pumps for Improving the Efficiency of Water Distribution Systems. Journal of Water Resources Planning and Management, v. I44, n. 9, 20I8. DOI: https://doi.org/IO.IO6I/(ASCE)WR.I943-5452.0000974

BROAD, D. R., MAIER, H. R.;DANDY, G. C. Optimal operation of complex water distribution systems using metamodels. Journal of Water Resources Planning and Management, v. I36, n. 4, p. 433-443, 2009.

BUREK, P. et al. Water futures and solution: fast track initiative (final report). Austria: IIASA, 2016. Disponível em: http://pure.iiasa.ac.at/id/eprint/I3008/I/WP-I6-oo6.pdf. Acesso em: 6 nov. 2019.

EMPRESA DE PESQUISA ENERGÉTICA - EPE. (20I8). Disponível em: http://epe.gov.br/pt/ abcdenergia/eficiencia-energetica. Acesso em: 8 nov. 2019.

CARPITELLA, S. et al. Multi-objective and multi-criteria analysis for optimal pump scheduling in water systems. In: International Conference on Hydroinformatics - HIC2OI8, I3., 20I8, Palermo. Proceedings [...] . Palermo: EPiC Engineering, 20I8. DOI: https://doi.org/I0.29007/vk44

CARRAVETTA et al. Energy production in water distribution networks: A PAT design strategy. Water resources management, v. 26, n. I3, p. 3947-3959, 20I2. DOI: https://doi.org/I0.1007/si1269-0I2OII4-I

CARRAVETTA, A.; FECAROTTA, O.; RAMOS, H. M. A new low-cost installation scheme of PATs for pico-hydropower to recover energy in residential areas. Renewable Energy, v. I25, p. I003-IOI4, 2018. DOI: https://doi.org/I0.IoI6/j.renene.2018.02.132

CARRAVETTA, A. et al. Reducing the Energy Dependency of Water Networks in Irrigation, Public Drinking Water, and Process Industry: REDAWN Project. Proceedings, v. 2, n. II, p. 68I, 2018. Trabalho apresentado no The EWaS International Conference on "Insights on the Water-Energy-Food Nexus". DOI: https://doi.org/I0.3390/proceedings2IIo68I

CHAPAllaZ, J. M.; EICHENBERGER, P.; FISCHER, G. Manual on pumps used as turbines. Braunschweig: Vieweg, I992. MHPG series harnessing water power on a small scale. Vol. II.

DORIGO, M.; DI CARO, G. Ant colony optimization: a new meta-heuristic. In: Congress on Evolutionary Computation-CEC99 (Cat. N. 99TH8406), I999, Washington. Proceedings [...]. Washington: IEEE, I999. p. I470-I477. DOI: https://doi.org/I0.IIo9/cec.I999.782657

EBERHART, R.; KENNEDY, J. A new optimizer using particle swarm theory. In: International Symposium on Micro Machine and Human Science, 6., I995, Nagoya. Proceddings [...].Nagoya: IEEE, I995. p. 39-43. DOI: https://doi.org/IO.IIO9/mhs.I995.4942I5

GOLDBERG, D. E.; KORB, B.; DEB, K. Messy Genetic Algorithms: Motivation, Analysis, and First Results. Complex systems, v. 3, n. 5, p. 4I5-444, I989. Disponível em: https://www.complex-systems. com/abstracts/vo3_io5_ao5/. Acesso em: 8 nov. 2019.

GOLDMAN, F. E.; MAYS, L. W. The application of simulated annealing to the optimal operation of water systems. In: Annual Water Resources Planning and Management Conference - WRPMD'99, 29., I999, Tempe. Proceedings [...]. Tempe: American Society of Civil Engineers, I999. DOI: https:// doi.org/I0.I06I/40430(I999)56 
GUANAIS, A. L. R.; COHIM, E. B.; MEDEIROS, D. L. Avaliação energética de um sistema integrado de abastecimento de água. Engenharia Sanitária e Ambiental, v. 22, n. 6, p. II87-IIg6, jul. 20I7. DOI: http://dx.doi.org/IO.I590/sI4I3-4I5220I7I46I80

HAMANAKA, S. Foreign Governmental Suppliers' Investment: Profit or Aid? The Case Study of Japanese City Water Bureau. In: CHAISSE, J. (Ed.). The Regulation of the Global Water Services Market. Cambridge: Cambridge University Press, 20I7. p. 220-24I. DOI: https://doi. org/ıo.IoI7/9781316678442.010

ISLAM, M. S.; BABEL, M. S. Economic analysis of leakage in the Bangkok water distribution system. Journal of Water Resources Planning and Management, v. I39, n. 2, p. 209-2I6, 20I3. DOI: https://doi.org/IO.IO6I/(ASCE)WR.I943-5452.0000235

JOWITT, Paul W.; XU, Chengchao. Optimal valve control in water-distribution networks. Journal of Water Resources Planning and Management, I990, II6.4: 455-472. DOI: https:// doi/abs/IO.IO6I/ (ASCE)0733-9496(I990)ir6:4(455)

JOWITT, P. W.; GERMANOPOULOS, G. Optimal pump scheduling in water-supply networks. Journal of Water Resources Planning and Management, v. II8, n. 4, p. 406-422, I992. DOI: https:// doi.org/ıo.Io6ı/(ASCE)0733-9496(1992)II8:4(406)

KOUGIAS, I. et al. Exploring the potential of energy recovery using micro hydropower systems in water supply systems. Water Utility Journal, v. 7, p. 25-33, 20I4. Disponível: https://www.ewra.net/ wuj/pdf/WUJ_20I4_07_03.pdf. Acesso em: 8 nov. 2019.

LANSEY, K. E.; AWUMAH, K. Optimal pump operations considering pump switches. Journal of Water Resources Planning and Management, v. I20, n. I, p. I7-35, I994. DOI: https://doi.org/IO.IO6I/ (ASCE)0733-9496(I994)I20:I(I7)

LIMA, G. M. Microgeração em Sistemas de Abastecimento de Água. 20I3. 70 f. Dissertação (Mestrado em Engenharia de Energia) - Universidade Federal de Itajubá, Itajubá, 20I3. Disponível em: http:// repositorio.unifei.edu.br/xmlui/handle/123456789/963. Acesso em: 8 nov. 2019.

LIMA, G. M. et al. Leakage Control and Energy Recovery Using Variable Speed Pumps as Turbines. Journal of Water Resources Planning and Management, v. I44, n. I, 20I7a. DOI: https:// doi.org/IO.IO6I/(ASCE)WR.I943-5452.0000852

LIMA, G. M.; BRENTAN, B.; LUVIZOTTO JUNIOR, E. Selection and location of Pumps as Turbines substituting pressure reducing valves. Renewable Energy, v. I09, p. 392-405, 20I7b. DOI: https:// doi.org/Io.IoI6/j.renene.2017.03.056

LIMA, G. M. Geração de Energia e Controle de Pressão em Redes de Abastecimento de Água Utilizando Bombas Funcionando como Turbina (Doutorado em Engenharia Civil) - Universidade Estadual de Campinas, 20I7c. Disponível em: http://repositorio.unicamp.br/bitstream/REPOSIP/331097/I/ Lima_GustavoMeirelles_D.pdf. Acesso em: 8 nov. 2019.

LIMA, G. M. et al. Trunk Network Rehabilitation for Resilience Improvement and Energy Recovery in Water Distribution Networks. Water, v. Io, n. 6, p. 693, 20I8. DOI: https://doi.org/10.3390/ wI0060693 
LINGIREDDY, S.; WOOD, D. J. Improved operation of water distribution systems using variablespeed pumps. Journal of Energy Engineering, v. I24, n. 3, p. 90-I03, I998. DOI: https://doi. org/IO.IO6I/(ASCE)0733-9402(I998)I24:3(90)

LÓPEZ-IBAÑEZ, M.; PRASAD, T. D.; PAECHTER, B. Multi-objective optimisation of the pump scheduling problem using SPEA2. In: Congress on Evolutionary Computation, 2005, Edinburgh. Proceedings [...].Edinburgh: IEEE, 2005. p. 435-442. DOI: https://doi.org/Io.IIO9/cec.2005.I5547I6 LÓPEZ-IBÁÑEZ, M., PRASAD, T. D.;PAECHTER, B. Ant colony optimization for optimal control of pumps in water distribution networks. Journal of Water Resources Planning and Management, v. I34, n. 4, p. 337-346, 2008. DOI: https://doi.org/Io.Io6I/(ASCE)0733-9496(2008)I34:4(337)

MALA-JETMAROVA, H.; SULTANOVA, N.; SAVIC, D. Lost in optimisation of water distribution systems? A literature review of system operation. Environmental modelling \& software, v. 93, p. 209-254, 20I7. DOI: https://doi.org/I0.I0I6/j.envsoft.2017.02.009

MANZI, D. et al. Dimensionamento ótimo de redes de distribuição de água com uso de métodos de otimização inspirados na natureza. Revista DAE, v. 2I2, n. 66, p. I6-3I, 20I8. DOI: https://doi. org/I0.4322/dae.2018.020

MARTINEZ, F. et al. Optimizing the operation of the Valencia water-distribution network. Journal of Hydroinformatics, v. 9, n. I, p. 65-78, 2007. DOI: https://doi.org/10.2166/hydro.2006.0I8

MCLEAN, B. Before the House Committee on Transportation and Infrastructure, Subcommittee on Water Resources and Environment. EPA online report, (2009).

MOSER, G.; PAAL, S. G.; SMITH, I. F. Performance comparison of reduced models for leak detection in water distribution networks. Advanced Engineering Informatics, v. 29, n. 3, p. 7I4-726, 2015. DOI: https://doi.org/10.I0I6/j.aei.20I5.07.003

MUHAMMETOGLU, A. et al. Evaluation of performance and environmental benefits of a full-scale pump as turbine system in Antalya water distribution network. Water Science and Technology: Water Supply, v. I8, n. I, p. I30-I4I, 20I8. DOI: https://doi.org/I0.2166/ws.20I7.087

ODAN F. K.; REIS, L. F. R.; KAPELAN, Z. Real-time multiobjective optimization of operation of water supply systems. Journal of Water Resources Planning and Management, v. I4I, n. 9, 20I5. DOI: https://doi.org/IO.IO6I/(ASCE)WR.I943-5452.0000515

PROGRESS ON SAFE TREATMENT AND USE OF WASTEWATER: piloting the monitoring methodology and initial findings for SDG indicator 6.3. 1. Geneva: World Health Organization and UNHABITAT, 20I8. 40 p. Disponível em: https://apps.who.int/iris/handle/Io665/275967 . Acesso em: 7 nov. 2019.

RAO, Z.; SALOMONS, E. Development of a real-time, near-optimal control process for waterdistribution networks. Journal of Hydroinformatics, v. 9, n.I, p. 25-37, 2007. DOI: https://doi. org/IO.IO6I/(ASCE)WR.I943-5452.0000515

RIBEIRO, L. C. L. J. Modelo híbrido multiobjetivo para obtenção de roteiros operacionais de bombas de rotação variável em instalações hidráulicas. 2007. I03 f. - Tese (Doutorado) - Faculdade de Engenharia Civil, Unicamp, Campinas, 2007. Disponível em: http://repositorio.unicamp.br/handle/ 
REPOSIP/258I78. Acesso em: 8 nov. 20I9.

RODRIGUES, Wlamir. Critérios para o uso eficiente de inversores de frequência em sistemas de bombeamento de água. 2007. 234p. Tese (Doutorado) - Universidade Estadual de Campinas, Faculdade de Engenharia Civil, Arquitetura e Urbanismo, Campinas, SP. Disponível em: http:// www.repositorio.unicamp.br/handle/REPOSIP/258I79. Acesso em: 9 ago. 2018.

ROSSMAN, L. A. EPANET 2: users manual. United States: EPA, 2000. Disponível em: https:// epanet.es/wp-content/uploads/20I2/Io/EPANET_User_Guide.pdf. Acesso em: 8 nov. 2019 .

SAVIC, D. A.; WALTERS, G. A.; SCHWAB, M. Multiobjective genetic algorithms for pump scheduling in water supply. In: AISB International Workshop on Evolutionary Computing, I997, Berlin. Proceedings [...]. Berlin: Springer, I997· p. 227-235. DOI: https://doi.org/I0.I007/BFboo27I77

SHAMIR, U.; SALOMONS, E. Optimal real-time operation of urban water distribution systems using reduced models. Journal of Water Resources Planning and Management, v. I34, n. 2, p. I8II85, 2008 .

SILVA FILHO, A. Q. da. Estudo de Diagnóstico Energético em Sistemas de Abastecimento. 2012. I9० f. Dissertação (Mestrado em Engenharia de Energia) - Universidade Federal de Itajubá, Itajubá, 20I2. Disponível em: http://repositorio.unifei.edu.br/xmlui/handle/ı23456789/II76. Acesso em: 8 nov. 20I9.

SOFFIA, C. et al. Hydropower potential from the drinking water systems of the Piemonte region. In: International Conference on Sustainable Energy \& Environmental Protection, 4., 20I0, Bari. Proceedings [...]. Bari, [s.n.], 20Iо. Disponível em: http://www.idrologia.polito.it/ claps/Papers/ PCo6I_Soffia.pdf. Acesso em: 8 nov. 2019.

STEPANOFF, A. J.; STAHL, H. A. Dissimilarity laws in centrifugal pumps and blowers. Journal of Engineering for Power, v. 83, n. 4, p. 38I-390, I96r. DOI: https://doi.org/IO.III5/I.36732I4

WAKEEL, M et al. Energy consumption for water use cycles in different countries: A review. Applied Energy, v. I78, p. 868-885, 20I6. DOI: https://doi.org/Io.IoI6/j.apenergy.20I6.o6.II4

WEGLEY, C.; EUSUFF, M.; LANSEY, K. Determining pump operations using particle swarm optimization. In: Joint Conference on Water Resource Engineering and Water Resources Planning and Management, 2000, Minneapolis. Proceedings [...].Minneapolis: ASCE Library, 20I2. DOI: https://doi.org/10.106I/405I7(2000)206

WYLIE, E. B.; STREETER, V. L.; SUO, L. Fluid transients in systems. Nova Jersey: Prentice Hall, I993. $464 \mathrm{p}$.

YU, G.; POWELL, R. S.; STERLING, M. J. H. Optimized pump scheduling in water distribution systems. Journal of optimization theory and applications, I994, 83.3: 463-488.

ZESSLER, U; SHAMIR, U. Optimal operation of water distribution systems. Journal of water resources planning and management, v. II5, n. 6, p. 735-752, I989. DOI: https://doi.org/IO.IO6I/ (ASCE) 0733-9496(I989)II5:6(735) 